\title{
INOVASI SISTEM INFORMASI APLIKASI MOBILE PAJAK DAERAH (SAMPADE) DALAM MENINGKATKAN PELAYANAN PUBLIK
}

\author{
Dewi Citra Larasati \\ Program Studi Administrasi Publik, FISIP Universitas Tribhuwana Tunggadewi Malang \\ e-mail: citralarasati311@gmail.com
}

\begin{abstract}
Abstrak: Sistem Informasi Aplikasi Mobile Pajak Daerah (SAMPADE) Kota Malang merupakan sebuah inovasi yang dilakukan oleh Badan Pelayanan Pajak Daerah (BP2D) Kota Malang berupa aplikasi berbasis teknologi informasi yang diharapkan memudahkan masyarakat atau wajib pajak dalam memenuhi pelayanan perpajakannya. Metode penelitian ini menggunakan metode penelitian kualitatif. Berdasarkan hasil penelitian terhadap pelaksanaan Inovasi Badan Pelayanan Pajak Daerah (BP2D) Kota Malang Melalui Sistem Informasi Aplikasi Mobile Pajak Daerah (SAMPADE) Dalam Meningkatkan Pelayanan Publik terdapat 5 indikator jenis inovasi yaitu inovasi proses, inovasi, metode, inovasi struktur organisasi, inovasi dalam hubungan, dan inovasi produk. Faktor pendukung dalam pelaksanaan dalam inovasi Sistem Informasi Aplikasi Mobile Pajak Daerah (SAMPADE) adalah disambut dengan baik oleh sebagian wajib pajak dan kerja sama dengan pihak luar yaitu CV. Sinergi. Serta dilengkapi dengan sarana dan prasana yang membantu dalam pelaksanaan sosialisasi kepada wajib pajak yaitu berupa 2 (dua) buah mobil khusus. Sedangkan untuk faktor penghambat dalam pelaksanaannya adalah inovasi Sistem Informasi Aplikasi Mobile Pajak Daerah (SAMPADE) ini terkadang terkena hacking dan server nya yang terkadang down dan masih rumit dalam penggunaannya. Serta masih ada beberapa wajib pajak yang belum mengerti menggunakan aplikasi ini dan beberapa wajib pajak juga belum mengerti IT dan lebih suka melakukan pelayanan perpajakan nya secara manual dengan pergi ke kantor Badan Pelayanan Pajak Daerah (BP2D) Kota Malang.
\end{abstract}

Kata Kunci: Inovasi, Sistem Informasi Aplikasi Mobile Pajak Daerah (SAMPADE), Pelayanan Perpajakan

Abstract: The Regional Tax Mobile Application Information System (SAMPADE) of Malang City is an innovation carried out by the Regional Tax Service Agency (BP2D) in Malang in the form of information technology-based applications which are expected to facilitate the public or taxpayers in fulfilling their tax services. This research method uses qualitative research methods. Based on the results of the research on the implementation of the Regional Tax Service Agency (BP2D) Innovation through the Regional Tax Mobile Application Information System (SAMPADE) in Improving Public Services, it has run quite well in terms of 5 indicators of innovation, namely process innovation, innovation, methods, structural innovation organization, innovation in relationships, and product innovation. Supporting factors in the implementation in the innovation of the Regional Tax Mobile Application Information System (SAMPADE) were welcomed by some taxpayers and cooperation with outside parties namely $C V$. Sinergy. And equipped with facilities and infrastructures that assist in the implementation of socialization to taxpayers, in the form of 2 (two) special cars. As for the inhibiting factor in its implementation is the innovation of the Regional Tax Mobile Application Information System (SAMPADE), sometimes it is hit by hacking and its servers are sometimes down and still complicated in its use. And there are still some taxpayers who do not understand using this application and some taxpayers also do not understand IT and prefer to do taxation services manually by going to the Malang Regional Tax Service Agency (BP2D) office.

Keywords: Innovation, Regional Tax Mobile Application Information System (SAMPADE), Tax Services 


\section{PENDAHULUAN}

Pesatnya perkembangan teknologi bertujuan untuk menjawab tantangan revolusi industri 4.0 yang sedang berlangsung saat ini. Perkembangan teknologi yang ada merupakan sebuah komoditas primer masyarakat secara umum. Sehingga kondisi semacam ini menjadikan sebuah tantangan bagi pemerintah untuk menyediakan sarana prasarana yang memadai, tersedianya sumber daya aparatur yang kompeten dan berkualitas untuk meningkatkan pelayanan publik. Hal ini juga menuntut pemerintah baik pusat maupun daerah untuk segera melakukan berbagai macam inovasi pelayanan publik. Inovasi pelayanan terhadap masyarakat diharapkan akan mempermudah, transparan, dan lebih cepat sesuai dengan standart pelayanan. Standart pelayanan publik di Indonesia diatur dalam Undang-Undang Nomor 25 Tahun 2009 tentang Pelayanan Publik Pasal 1 ayat 7.

Hal ini menjadi tantangan tersendiri bagi Pemerintah Kota Malang dalam memberikan pelayanan publik di bidang perpajakan. Pelayanan Perpajakan untuk Pajak Daerah di Kota Malang diselenggarakan oleh Badan Pelayanan Pajak Daerah (BP2D) Kota Malang. Namun pelayanan perpajakan selama ini terkendala oleh lokasi BP2D Kota Malang yang jauh dari pusat kota sehingga masyarakat terjebak oleh keterbatasan waktu, jarak, dan kesibukan aktivitas lainnya sehingga menemui kesulitan dalam menjangkaunya. Untuk mengatasi permasalahan tersebut BP2D Kota Malang membuat sebuah inovasi untuk mendekatkan pelayanan perpajakan kepada masyarakat Kota Malang dengan pelayanan pajak yang memanfaatkan penggunaan teknologi informasi berbasis online.

Menurut Larasati (2019) Tantangannya yang dihadapi dalam melaksanakan inovasi berbasis $e$ - government adalah pemerintah mampu memberikan penyediaan sarana prasarana yang memadai dan pemenuhan sumber daya aparatur yang kompeten serta berkualitas untuk meningkatkan pelayanan publik. Hal ini juga menjadi tantangan tersendiri bagi Pemerintah Kota Malang dalam memberikan pelayanan perpajakan. Pelayanan Perpajakan untuk Pajak Daerah diselenggarakan oleh Badan Pelayanan Pajak Daerah (BP2D) Kota Malang. Pelayanan perpajakan selama ini terkendala oleh lokasi Badan Pelayanan Pajak Daerah (BP2D) Kota Malang yang jauh dari pusat kota sehingga masyarakat dihadapkan oleh keterbatasan waktu, jarak, dan kesibukan aktifitas lainnya. Sehingga untuk menjawab tantangan tersebut, Pemkot Malang dalam hal ini BP2D Kota Malang pada tanggal 20 Mei 2018, meluncurkan sebuah inovasi berupa aplikasi perpajakan yaitu Sistem Informasi Aplikasi Mobile Pajak Daerah yang dikenal dengan istilah SAMPADE. Diharapkan dengan adanya SAMPADE ini akan bisa meningkatkan dan memudahkan pelayanan publik terhadap masyarakat, khususnya para Wajib Pajak (WP) untuk mengetahui informasi tentang perpajakan daerah secara aktual dan efisien, mulai dari informasi terkait objek pajak, informasi tagihan dan tunggakan, informasi sistem pembayaran dan pengumuman pajak daerah. Masyarakat juga bisa melakukan konsultasi pajak daerah hingga mengunduh peraturan pajak daerah melalui aplikasi SAMPADE tanpa harus ke kantor Badan Pelayanan Pajak Daerah (BP2D) Kota Malang.

Berdasarkan penjelasan latar belakang tersebut, penelitian ini bertujuan 1) untuk Mengetahui dan menganalisis inovasi Sistem Informasi Aplikasi Mobile Pajak Daerah (SAMPADE) dalam meningkatkan pelayanan publik dan 2) untuk mengidentifikasikan faktor pendukung dan faktor penghambat yang mempengaruhi dalam pelaksanaan pelayanan pajak melalui Sistem Informasi Aplikasi Mobile Pajak Daerah (SAMPADE). 
Melalui tujuan penelitian tersebut, teori yang dapat digunakan dalam penelitian ini adalah pengertian inovasi berdasarkan Peraturan Menteri Pendayagunaan Aparatur Negara dan Reformasi Birokrasi Republik Indonesia Nomor 30 Tahun 2014 Tentang Pedoman Inovasi Pelayanan Publik bahwa inovasi adalah proses kreatif penciptaan pengetahuan dalam melakukan penemuan baru yang berbeda dan/atau modifikasi dari yang sudah ada. Sedangkan, inovasi pelayanan publik adalah terobosan jenis pelayanan baik yang merupakan gagasan/ide kreatif orisinal dan/atau adaptasi/modifikasi yang memberikan manfaat bagi masyarakat, baik secara langsung maupun tidak langsung. Dengan kata lain inovasi pelayanan publik sendiri tidak mengharuskan suatu penemuan baru, tetapi dapat merupakan suatu pendekatan baru yang bersifat kontekstual dalam arti inovasi tidak terbatas dari tidak ada kemudian muncul gagasan dan praktik inovasi, tetapi dapat berupa inovasi hasil dari perluasan maupun peningkatan kualitas pada inovasi yang ada. Kemudian menurut Damanpour dalam Larasati (2017) bahwa sebuah inovasi dapat berupa produk atau jasa yang baru, teknologi proses produksi yang baru, sistem struktur dan administrasi baru, atau rencana baru bagi anggota organisasi.

Menurut Lewis dan Gilman dalam Hayat, (2017: 21) pelayanan publik adalah kepercayaan publik. Pelayanan publik dilaksanakan secara bertanggung jawab dan sesuai dengan ketentuan dan peraturan yang ada. Nilai akuntabilitas pelayanan yang diberikan dapat memberikan kepercayaan kepada masyarakat tentang pelayanan yang diberikan. Pertanggungjawaban terhadap aspek yang dilayani adalah bagian dari pemenuhan terhadap pelayanan publik untuk menaikkan grade kepercayaan dari masyarakat. Kepercayaan masyarakat adalah sebagai dasar untuk mewujudkan tercapainya pemerintahan yang baik. Dari beberapa pendapat mengenai pelayanan publik tersebut dapat disimpulkan bahwa pelayanan publik dapat dimaknai sebagai aktivitas pelayanan yang dilakukan oleh lembaga pemerintah untuk memenuhi kebutuhan masyarakat.

\section{METODE}

Penelitian mengenai SAMPADE ini menggunakan metode kualitatif dengan rumusan masalah deskriptif. Dalam memperoleh data, penelitian ini menggunakan teknik purposive sampling (melakukan wawancara kepada beberapa pihak yang dianggap mengetahui permasalahan SAMPADE) dan teknik pengumpulan data yang digunakan adalah melakukan observasi secara langsung dan melakukan wawancara. Dalam hal keabsahan data, penelitian ini dianalisis dengan cara interaktif serta berlangsung secara terus menerus mulai dari data collecting sampai tuntas dan data yang dicari sudah jenuhkmudian data tersebut di display kemudian data di reduction dan di analisis kemudian conclusion drawing/verification.

\section{HASIL DAN PEMBAHASAN}

\section{1) Pelaksanaan Inovasi Sistem Informasi Aplikasi Mobile Pajak Daerah (SAMPADE) Dalam Meningkatkan Pelayanan Publik}

Badan Pelayanan Pajak Daerah (BP2D) Kota Malang telah menerapkan sebuah aplikasi khusus yang berpedoman pada Peraturan Presiden Nomor 95 tahun 2018 tentang Sistem Pemerintahan Berbasis Elektronik. Dijelaskan dalam Perpres ini bahwasanya Aplikasi Khusus Pemerintah merupakan aplikasi Sistem Pemerintahan Berbasis Elektronik (SPBE) yang dibangun, dikembangkan, digunakan, dan dikelola oleh instansi pemerintah baik pusat maupun instansi pemerintah daerah supaya memenuhi kebutuhan khusus yang bukan kebutuhan instansi pusat dan pemerintah daerah lainnya.

Aplikasi Sistem Informasi Aplikasi Mobile Pajak Daerah (SAMPADE) ini merupakan sebuah aplikasi khusus yang dijadikan sebuah inovasi Pemerintah Kota Malang melalui Badan 
Pelayanan Pajak Daerah (BP2D) untuk memberikan pelayanan prima dengan berbagai kemudahan bagi Wajib Pajak (WP) dalam mengetahui informasi tentang perpajakan daerah secara actual dan real time. Dengan aplikasi ini, masyarakat dapat menghemat waktu dan bisa mendapatkan pelayanan dengan baik. Aplikasi SAMPADE ini bisa diunduh melalui playstore menggunakan smartphone dengan sangat mudah. Setelah mengunduh SAMPADE, Wajib pajak dapat memperoleh beragam informasi yang terdiri dari pengecekan profil subjek dan objek pajak, pengumuman, pelaporan, pengecekan status tagihan pajak, konfirmasi pembayaran, update pajak daerah, terdapat menu khusus untuk pengajuan mutasi atau perubahan objek pajak, dan untuk mendownload peraturan dengan melayani 9 (sembilan) jenis pajak daerah yang meliputi: Pajak Restoran, Pajak Bumi dan Bangunan (PBB), Pajak Reklame, Pajak Parkir, Pajak BHTB, Pajak Hotel, Pajak Hiburan, Pajak Penerangan Jalan (PPJ), dan Pajak Air Tanah. Selain itu, masyarakat juga bisa melakukan konsultasi pajak daerah dengan operator hingga mengunduh peraturan pajak daerah dari aplikasi Sistem Informasi Aplikasi Mobile Pajak Daerah (SAMPADE) ini. Berikut ini adalah tampilan SAMPADE yang menunjukkan jenis-jenis pelayanan pajak yang terdapat dalam SAMPADE sebagaimana berikut:

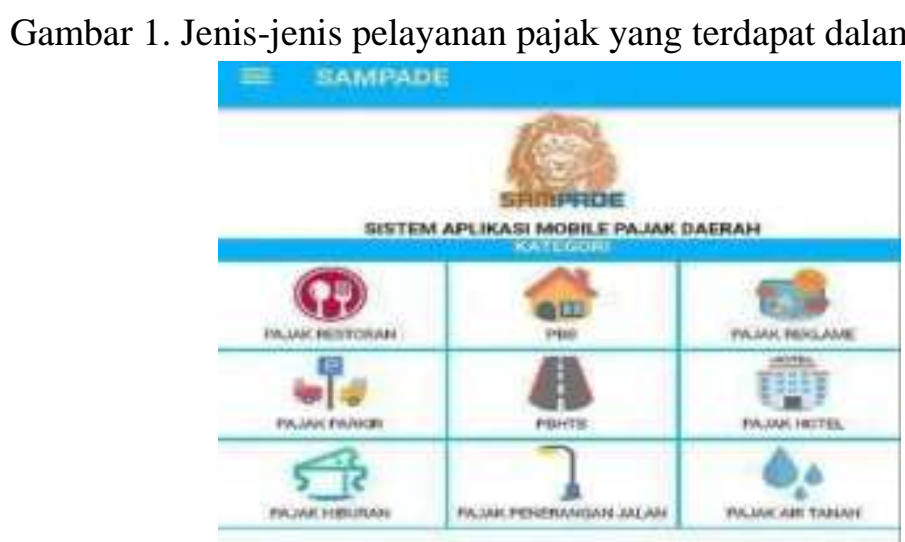

Sumber: SAMPADE BP2D Kota Malang, 2019

Badan Pelayanan Pajak Daerah (BP2D) melakukan pengembangan agar Inovasi Sistem Informasi Aplikasi Mobile Pajak Daerah (SAMPADE) dapat berkembang dengan baik serta mudah digunakan oleh masyarakat atau wajib pajak dengan cara perbaikan view lebih compact, penambahan fitur chat dengan petugas pajak, perbaikan fitur laporan objek pajak, perbaikan minor bug, dan pergantian tampilan aplikasi, ini salah satu contoh dari metode dalam pengembangan. Hal ini berkaitan dengan asas-asas pelayanan publik yaitu transparansi, yaitu bersifat terbuka mudah dan dapat diakses oleh semua pihak yang memerlukan dan disediakan secara memadai serta mudah dimengerti.

Melalui teori jenis inovasi menurut Ancok dalam Mulyadi (2018: 80), Pelaksanaan SAMPADE dalam meningkatkan pelayanan publik dapat dianalisis sebagaimana berikut ini:

\section{Inovasi proses}

SAMPADE pada dasarnya merupakan sebuah inovasi proses dalam pelayanan perpajakan. Untuk menggunakan aplikasi ini, Wajib pajak (WP) dapat langsung mendownload aplikasi tersebut di smartphone melalui playstore. Ini adalah salah satu contoh inovasi proses. Inovasi proses dapat dipahami sebagai upaya organisasi untuk meningkatkan kualitas proses kerja baik di lingkungan kerja internal maupun eksternal yang lebih efisien dan sederhana. Di awal peluncurannya, SAMPADE disambut dengan baik oleh masyarakat walaupun sebagian masyarakat belum juga menggunakan aplikasi ini dikarenakan minimnya sosialisasi dan info 
mengenai SAMPADE serta masyarakat belum mengetahui cara mengoperasikannya lebih sering melakukan pelayanan perpajakannya secara manual dengan datang ke kantor Badan Pelayanan Pajak Daerah (BP2D) Kota Malang. Walaupun Badan Pelayanan Pajak Daerah (BP2D) Kota Malang telah melakukan sosialisasi kepada wajib pajak terkait inovasi Sistem Informasi Aplikasi Mobile Pajak Daerah (SAMPADE) di Mall Olympic Garden, Radar Malang, dan Ramayana disertai pendampingan kepada wajib pajak dalam penggunaannya. Namun, inovasi proses ini harus terhenti dikarenakan adanya serangan hacker yang membuat aplikasi ini bisa di download namun tidak bisa dioperasikan.

\section{Inovasi metode}

Inovasi metode dapat dipahami sebagai sebuah strategi dengan banyak cara dan teknik baru untuk mencapai suatu hasil yang jauh lebih baik. Beberapa kriteria yang terdapat dalam inovasi metode adalah:

1) Bentuknya adalah sebuah kebijakan organisasi yang mengatur sebuah cara baru dalam melakukan proses perbaikan kerja organisasi. Cara baru ini dapat menyentuh ke berbagai ranah lainnya seperti : cara dalam mengambil keputusan, cara dalam membuat produk, cara dalam memberikan pelayanan, dan sebagainya.

2) Inovasi di implementasikan ketika cara atau metode lama yang digunakan organisasi dirasa sudah tidak lagi efektif dan menguntungkan.

3) Inovasi yang ada bersifat makro dan dapat diterapkan untuk bidang yang luas,

Melihat ketiga ciri tersebut, SAMPADE juga termasuk dalam inovasi metode, hal ini dikarenakan SAMPADE sebagai strategi, cara, dan teknik baru untuk mencapai hasil yang lebih baik dalam pelayanan perpajakan. Sehingga inovasi metode akan lebih baik lagi dengan cara perbaikan tampilan dan penambahan fitur aplikasi.

\section{Inovasi dalam hubungan}

Untuk menunjang agar pelayanan perpajakan melalui SAMPADE berjalan dengan baik, Badan Pelayanan Pajak Daerah (BP2D) Kota Malang bekerja sama dengan pihak luar yaitu CV Sinergi. Hal ini juga sebagai perwujudan dari komitmen BP2D Kota Malang sebagai Zona Integritas Bebas Korupsi. CV Sinergi bertugas sebagai pihak ketiga yang berperan mengembangkan SAMPADE termasuk jika ada maintanance. Inovasi dalam hubungan juga dilakukan dengan Bank Jatim, karena berhubungan dengan pembayaran secara online, sehingga tidak ada lagi pembayaran yang dititipkan kepada pegawai BP2D Kota Malang.

Untuk pihak internalnya, Badan Pelayanan Pajak Daerah (BP2D) Kota Malang bekerja sama antar struktur organisasi yang mengelolanya yaitu Bidang Pendataan, Pendaftaran, dan Penetapan, Bidang Pengembangan Potensi dan Bidang IT dengan saling membantu, mengevaluasi dan saling mendukung.

\section{Inovasi produk}

SAMPADE yang berbasis teknologi online kelanjutan dari proyek pelayanan ajak online sebelumnya yang diluncurkan pada tahun 2013. Inovasi ini berisi fitur-fitur pelayanan perpajakan yang terdiri dari pengecekan profil subjek dan objek pajak, pengumuman, pelaporan, pengecekan status tagihan pajak, konfirmasi pembayaran, update pajak daerah, dan download peraturan. Dengan melayani 9 (sembilan) jenis pajak daerah yang meliputi: Pajak Restoran, PBB, Pajak Reklame, Pajak Parkir, PBHTB, Pajak Hotel, Pajak Hiburan, Pajak Penerangan Jalan, dan Pajak Air Tanah.

\section{Inovasi strategi}

Inovasi strategi merupakan sebagai pola tindakan yang dipilih untuk mewujudkan visi dan misi. Strategi membentuk suatu pola pengambilan keputusan dalam mewujudkan visi dan 
misi organisasi. Strategi mengarahkan seluruh sumber daya secara efektif dalam mencapai tujuan dan sasaran yang telah ditetapkan. SAMPADE adalah inovasi strategi yang dilakukan oleh BP2D untuk mewujudkan visi dan misi yang dimiliki oleh BP2D yaitu "Terwujudnya Penerimaan Pajak Daerah yang Optimal" dengan"Mengoptimalkan Penerimaan Pajak Daerah Melalui Pelayanan Publik yang Profesional, Akuntabel, dan Berorientasi pada Kepuasan Masyarakat".

BP2D juga melakukan sebuah strategi agar wajib pajak mau menggunakan Inovasi Sistem Informasi Aplikasi Mobile Pajak Daerah (SAMPADE) dengan memperkenalkan inovasi tersebut melalui media pemberitaan di media massa, media sosial resmi milik Badan Pelayanan Pajak Daerah (BP2D) seperti instagram, facebook, dan sebagainya serta melakukan sosialisasi melalui sarana prasarana berupa 2 (dua) buah mobil khusus untuk melakukan sosialisasi Inovasi Sistem Informasi Aplikasi Mobile Pajak Daerah (SAMPADE) dan menyebarkan brosur tentang Sistem Informasi Aplikasi Mobile Pajak Daerah (SAMPADE) serta mengadakan pendampingan kepada wajib pajak dalam menggunakan Sistem Informasi Aplikasi Mobile Pajak Daerah (SAMPADE) dan mengembangkan sistem aplikasi tersebut menjadi lebih sederhana agar lebih mudah digunakan oleh wajib pajak.

\section{Faktor-Faktor Yang Mempengaruhi Pelaksanaan Inovasi Badan Pelayanan Pajak Daerah (BP2D) Kota Malang Melalui Sistem Informasi Aplikasi Mobile Pajak Daerah (SAMPADE) Dalam Meningkatkan Pelayanan Publik. \\ a. Faktor Pendukung}

Faktor yang mendukung dalam pelaksanaan SAMPADE adalah adanya kerja sama yang baik antar struktur organisasi yang mengelolanya dan dukungan motivasi yang dilakukan oleh Kepala BP2D. Selain itu, kelengkapan sarana dan prasarana seperti prasarana kerja, peralatan kerja dan pendukung lainnya yang memadai termasuk dalam dukungan pelaksanaan sosialisasi SAMPADE yaitu berupa 2 (dua) buah mobil khusus yang dilengkapi komputer di dalamnya.

\section{b. Faktor Penghambat}

Faktor penghambat yang ditemui di dalam pelaksanaan inovasi SAMPADE berasal dari internal dan eksternal BP2D. Faktor penghambat secara internal yang dihadapi adalah sering terjadi server down dan tidak adanya anggaran untuk maintanance di tahun 2019. Sehingga dalam masalah seperti ini, perlu adanya anggaran khusus untuk menjaga keberlangsungan SAMPADE baik dalam hal maintanance dan perbaikan serta penambahan jaringan sehingga pelayanan bisa lebih baik lagi. Faktor internal lainnya, Pegawai BP2D yang memiliki kompetensi di bidang IT hanya berjumlah dua orang. Dan kedua pegawai ini juga memiliki tanggung jawab menangani semua proyek IT yang ada di BP2D sehingga terjadi penumpukan beban kerja terhadap dua pegawai tersebut. Sehingga perlu adanya pelatihan khusus IT pada beberapa pegawai lainnya untuk turut membantu membackup pelaksanaan SAMPADE.

Sedangkan faktor eksternal yaitu adanya hacker yang membuat aplikasi SAMPADE menjadi tidak berfungsi. aplikasi ini bisa di download namun tidak bisa digunakan. Faktor penghambat eksternal lainnya yang ditemui pada Wajib Pajak (WP) yaitu masih ada beberapa dari wajib pajak yang belum tahu cara menggunakan aplikasi ini serta beberapa dari wajib pajak yang juga masih belum mengerti IT (gagap teknologi/gaptek). Selain itu pula, ketika BP2D Kota Malang melakukan sosialisasi dan pendampingan kepada wajib pajak dalam menggunakan inovasi SAMPADE ini, banyak WP yang mengeluh bahwa tidak ada kuota untuk mengunduh aplikasi tersebut, serta tidak cukup ruang penyimpanan pada handphone pada wajib pajak. Sehingga inovasi SAMPADE hanya dijadikan opsi saja oleh wajib pajak dan lebih suka melakukan pelayanan perpajakannya secara manual dengan pergi ke kantor BP2D Kota Malang. 
JISIP: Jurnal Ilmu Sosial dan IlmuPolitik

ISSN. 2442-6962

Vol. 9 No. $1(2020)$

\section{KESIMPULAN}

Berdasarkan hasil pembahasan dapat disimpulkan bahwa 1) Pelaksanaan Inovasi Badan Pelayanan Pajak Daerah (BP2D) Kota Malang Melalui Sistem Informasi Aplikasi Mobile Pajak Daerah (SAMPADE) Dalam Meningkatkan Pelayanan Publik terdapat lima unsur inovasi (inovasi proses, inovasi, metode, inovasi struktur organisasi, inovasi dalam hubungan, dan inovasi produk) dan dalam pelaksanaannyapun masih kurang maksimal dikarenakan munculnya beberapa faktor penghambat yang belum teratasi dengan baik, 2) faktor yang berperan dalam pelaksanaan SAMPADE terdiri dari faktor pendukung dan penghambat. Kerja sama yang baik dan dukungan baik motivasi kelengkapan sarana dan prasarana yang ada di dalam BP2D merupakan faktor pendukung utama dalam pelaksanaan SAMPADE. Sedangkan untuk faktor penghambat berasal dari internal dan eksternalnya adalah tidak adanya anggaran maintanance, munculnya hecker, dan masih rendahnya mindset wajib pajak mengenai pelayanan pajak online sehingga membuat WP lebih memilih melakukan pelayanan datang langsung ke kantor BP2D Kota Malang.

Berdasarkan pembahasan yang telah dilakukan, maka dirumuskan beberapa saran sebagaimana berikut: 1) Perlu adanya keberlanjutan penganggaran pada tahun-tahun berikutnya dalam menjaga keberlangsungan maintanance sistem, penambahan jaringan dan penguatan pengamanan sehingga kasus hacking tidak terulang kembali. 2) Perlunya pelatihan khusus IT terhadap beberapa pegawai BP2D untuk membantu membackup pelaksanaan SAMPADE dan 3) Perlu adanya keberlanjutan sosialisasi kepada Wajib Pajak supaya bisa merubah mindset dari pelayanan datang langsung ke kantor menjadi pelayanan pajak secara online

\section{DAFTAR PUSTAKA}

Hayat. 2017. Manajemen Pelayanan Publik. Jakarta: Rajawali Pers.

Larasati, D. 2019. ANALISIS ELEMEN SUKSES E-GOVERNMENT DALAM IMPLEMENTASI SISTEM INFORMASI APLIKASI MOBILE PAJAK DAERAH (SAMPADE) KOTA MALANG. Conference on Innovation and Application of Science and Technology (CIASTECH), 2(1), RHP 93-100. Retrieved from http://publishingwidyagama.ac.id/ejournal-v2/index.php/ciastech/article/view/1091/894

Larasati, D. C. 2017. Evaluasi Program Inovasi "Sunset Policy“ Di Kota Malang Guna Menurunkan Angka Tunggakan Pajak Bumi dan Bangunan Perkotaan, REFORMASI, 7 (1) : 21-30

Mukarom, Zaenal. Dkk. 2015. Manajemen Pelayanan Publik. Bandung: Cv Pustaka Setia. Mulyadi, Deddy. Dkk. 2018. Administrasi Publik Untuk Pelayanan Publik. Bandung: Alfabeta.

Peraturan Menteri Pendayagunaan Aparatur Negara dan Reformasi Birokrasi Republik Indonesia Nomor 30 Tahun 2014 Tentang Pedoman Inovasi Pelayanan Publik.

Peraturan Presiden Nomor 95 Tahun 2018 Tentang Sistem Pemerintahan Berbasis Elektronik Sugiyono. 2014. Metode Penelitian Kuantitatif Kualitatif Dan R\&D. Bandung: Alfabeta. Undang-Undang Nomor 25 Tahun 2009 Tentang Pelayanan Publik. Undang-undang Republik Indonesia Nomor 23 Tahun 2014 Tentang Pemerintahan Daerah. 